\title{
Social science and moral dialogue
}

\section{Wolfgang Streeck}

Max Planck Institute, Cologne, Germany

Why have so many of us who are doing institutional analyses of the economyin-society been so reluctant, quite unlike Amitai Etzioni, to elaborate a noneconomistic micro foundation for our sort of social science? In part, this is because the neoclassical account of human behaviour, being the most immunized ideational construct this side of medieval scholasticism, is such an unpleasant opponent. Depending on the situation, it can with breathtaking flexibility be presented by its proponents as an analytical model, a strategic prescription or an ontological anthropology. Point out its empirical emptiness, and it was never supposed to be empirically true. Attack its prescriptions, and it is just a 'value-free' analytical tool. Ridicule its ontology, and it is merely a practical instrument for anyone who happens to want to maximize his or her utility.

Faced with such an elusive opponent, many of those working on the evolution of socio-economic institutions, or on the relationship between social institutions and economic outcomes, have simply given up talking about individual behaviour and the motives that drive it. By moving on without further ado to the macro properties of societies, however, we have laid ourselves open to the charge of being unable to produce a 'proper micro foundation' for our work. Coming from where it comes, this should not overly concern us - were it not that by leaving the field, we leave it to our opponent. 'It takes a theory to beat a theory', we hear, and unfortunately this rings true to most people even if the theory to beat merely pretends to be one. By implicitly holding individual motivation constant and observing only changes in the institutions supporting and constraining it-in other words, by avoiding explicit assumptions about individuals or 'human nature'-we have created a vacuum that draws in whatever is on offer outside social theory. This may be why the vulgarities of 'rational choice' have become so popular among younger sociologists and political scientists: they fill the gap we left when we became tired of scholastic debates about 'rationality' and 'utility'.

But there is more to this than just the difficulties of nailing down the opponent. Two other reasons seem to be at least equally important. First, any non-rational, more-than-just-egoistic or, in Etzioni's terms, deontological conception of human behaviour runs the risk of being perceived as value-laden and being denounced as 'moralizing'. Moralizing is against the scientific spirit to which we are committed and it is not well received by our colleagues. It is also not cool. ('Immoralizing', of course, is: that is, conceptually transforming moral into utility-maximizing behaviour.) Since a moral conception of human agency underlines the responsibility to distinguish between moral and maximizing action, it would come close to an 
exhortation to do what is 'right' rather than what is convenient. However, people resent moral exhortation, and National Science Foundations are unwilling to pay for it. Also, taking the 'moral dimension' of social science seriously may have far-reaching implications for its practical use that, I believe, go far beyond what Etzioni indicates in his paper-invalidating whatever technocratic aspirations social science may still harbour.

More on this later. If a deontological conception of human action were 'prescriptive', rather than analytical and scientific, it would certainly be no more so than a neoclassical one. But neoclassical economics tends to treat moral commitment as a lack of clear thinking interfering with a person's proper pursuit of self-interest. Alternatively, it treats moral commitment as latently functional for rational egoists acting under imperfect information. In this way, what is at best an immoral theory can make itself appear as though it were no moral theory at all. By contrast, the sort of anthropology that Etzioni envisages can dress itself up in whatever scientistic way it wants, it will always be liable to be received as 'preaching. Here we touch on the essentially human condition that, whereas animals have instincts, we have moral obligations, and the capacity to choose whether or not we shall honour them. Thus while the preaching of rational egoism is not 'preaching' but science, the preaching of moral responsibility can be denounced as exactly that. It crosses the borderline between theory and practice, between social science and social life, and deploys the authority of science to inform individuals of what they would often be happy to forget: that their free choices are also moral choices.

The second reason, I believe, why the battlefield tended to be left to the neoclassical paradigm is that a substantive concept of human nature is much harder to defend than a formal one. Empirical generalizations on human behaviour are notoriously difficult. For each example there seems to be a counter-example. The better established a generalization is, the more trivial it appears to be. Not only does one face the logical difficulties of induction, but one also runs the risk of treating historically contingent behaviour patterns as if they were natural laws. I for one have mostly felt quite comfortable with a very general, 'open' working concept of the human actor that allowed me to proceed without loss of time to the analysis of the macro-social, aggregate phenomena that interest me. As a graduate student about 30 years ago I once wrote a term paper along these lines for my then major professor at Columbia, Amitai Etzioni, using the young Marx as my main reference. Man is not, but makes himself in history and society. Amitai certainly, and probably rightly, does not remember the paper, as evidenced by his admirable ambition to found a new social science paradigm on an inventory of what we know to be true of human behaviour. I am afraid that a 'social genome project' of the kind he suggests may be vulnerable to the same sort of criticism that is rightly levelled against its biological counterpart. The real challenge is not to identify the elements but the generative mechanisms that combine them into the complex phenomena that alone interest us. 
In the end, the problem may not be an epistemological but a political one. If human behaviour is by definition moral, it is most appropriately and, presumably, most effectively influenced by moral argument. Public policy that took this into account would become indistinguishable from moral discourse. For example, instead of making pragmatic adjustments to institutional arrangements behind the backs of the individuals who act within them, it would have to deal directly with the latter, i.e. with the micro foundation of such institutions. In this, it would differ fundamentally from a utility-maximizing concept of human action. What would be different is that a 'moral' concept of public policy based on a moral image of human agency would try to influence individual behaviour primarily by appealing to collective values. Treating social science as based on a process of dialogue instead of on objective foundations would transform technocratic social engineering into civic debate. In the long run, it would abolish the distinction between policymakers as the subjects and policy-takers as the objects of political decision-making. While I am not sure if this is what Etzioni has in mind, it may be the logical consequence if one accepts the premise that utility-maximizing human action is and must be embedded in a larger context of moral values and obligations.

One can see why one might not want to go all this way. Prophets are not popular, especially those doing prophecy for a living. In his day, Max Weber was conscious of the resentment against 'salaried prophets'. A more indirect, less visible, 'institutionalist' approach to governance that aims at influencing collective conditions by changing the institutions that constrain and support individual behaviour may hope to avoid this resistance. Often, especially on the Left, it coincides with an implicit belief that human behaviour and preferences are fundamentally benevolent: it is not the people who are wrong, but the institutions ruling them. Accompanying this belief tends to be a normatively based reluctance to put individuals under moral pressure - a respect for individual autonomy that also underlies the liberal rejection of 'preaching'. It could be argued that public appeals to social duties, like the duty to draw unemployment benefit only when actively seeking a job, are far less manipulative and 'repressive' than seeking to change people's behaviour behind their backs by rebuilding from above the institutional structures that condition their choices. Actually what often passes as liberal rejection of moral manipulation may be no more than fear of the flak one can expect when publicly raising issues of moral duty - a flak Amitai Etzioni knows well and clearly fears not. It may also be an expression of resignation in a society where it seems that moral argument does not cut much ice. People simply refuse to listen, and when confronted with a choice between public duty and private utility, they will all too often opt for the latter. In this case, good policy would consist above all of institutionally foreclosing that option. This sort of pessimism Amitai does not share; or does he?

Unlike Habermas, Etzioni does not propose to abandon social science for moral philosophy and public dialogue. Etzioni's socio-economics are probably best 
understood as a 'third way': an attempt to use the available social science knowledge to reinforce moral argument; or, in the language of one of his most important books, the Comparative Analysis of Complex Organizations, to replace utilitarian and coercive with normative social control. Putting positive social science at the service of improving moral communication, however, involves a difficult balancing act. While the socio-economist à la Etzioni must be and wants to be a moralist, he or she also remains, and insists on remaining, a scientist. Moral dialogue, however, unless it is only a caricature of itself, not only accepts its objects as subjects but also must put its objectives at their disposal.

What distinguishes the socio-economics Etzioni suggests we pursue from the vulgar materialism-cum-naturalism of neoclassical economics? With a standardized curriculum, recognized degrees and established career paths for its graduates, socio-economics might be tempted to market itself to the powers-that-be as the applied discipline with the larger bag of superior tricks: tricks that work because they take into account the social nature of human beings, instead of mistakenly treating them as isolated, utility-maximizing individuals. Building and operating its own set of naturalistic abstractions, socio-economics would differ from standard economics in that it would get to the individual where it is most vulnerable: at its social and moral nature. For example, the specialist knowledge of a future discipline of socioeconomics might be called upon to engineer the transformation of large transnational firms into a moral communities, with less distributional conflict and higher productivity - like a new 'human relations' school concerned not just with the workplace but ultimately with society at large. The irony is that deep down a discipline of socio-economics would know that in practice it is unlikely to be any more successful than its human relations predecessor, given that the effectiveness of moral argument ultimately depends on its authenticity, and this is to say its openness with respect to its results. It is not easy to build moral commitment top-down, without debate. However, a discipline that would tell its clients this as its main message will not long carry their favour. What executives or politicians want to hire university graduates who keep telling them, true or not, that ultimately problems of governance are problems of moral credibility? Compared with this, I am sure, decision-makers are quite willing to make do with the knowledge offered by neoclassical economists, less sophisticated as it may be. If occasional policy failure is avoided only at the cost of a loss of power, occasional policy failure is just fine. Socioeconomics faces a choice. It might seek to be a discipline competing for jobs and research money with other providers of social control technology. Alternatively, it could be a set of ideas contributing to a better-informed public understanding of the relationship between economy and society, and of the role of moral values and material interests in both. 